\title{
ANÁLISIS DEL FENÓMENO DE LA TRATA DE PERSONAS DESDE LA PERSPECTIVA DE LOS DERECHOS HUMANOS
}

\author{
Autora: María Reina Peñas \\ mariareinape@gmail.com \\ Universidad Pontificia Comillas
}

\begin{abstract}
Resumen
La trata de personas es un delito que vulnera gravemente los derechos humanos de las víctimas que pasan a ser invisibles. Está definido por la Organización de las Naciones Unidas (2000) como "una secuencia de actividades delictivas cuyo propósito incluye diversas formas de explotación". Es considerada una forma contemporánea de esclavitud que ha ido evolucionado con el tiempo debido al proceso de la globalización. Este delito tiene distintos fines entre los que se encuentran sobre todo la explotación sexual y la explotación laboral, pero también la esclavitud y prácticas similares, la extracción de órganos, etc. En ocasiones existe cierta confusión entre el delito de trata de personas y otros delitos, por ello es necesario analizarlo desde distintas perspectivas para poder garantizar la protección de las víctimas. En este trabajo se ha hecho una revisión sobre las distintas perspectivas: enfoque de centralización de la víctima, enfoque de criminalización del delito o
\end{abstract}


de lucha contra la delincuencia, enfoque de género y enfoque basado en los derechos humanos. Se ha centrado el estudio en la última perspectiva basada en los derechos humanos por la grave violación de éstos que supone viéndose las víctimas afectadas en todos los aspectos de su esfera jurídica al ser cosificadas.

Palabras clave: Trata de personas; derechos humanos; delito de trata; esclavitud; Explotación.

\title{
The analysis of trafficking in persons from a human rights perspective
}

\begin{abstract}
Human trafficking is a crime that seriously infringe the victims' human rights who become invisible. It is defined by the United Nations (2000) like "a sequence of criminal activities whose purpose includes different forms of exploitation". This crime is considered a contemporary form of slavery that has evolved with globalization. It has different purposes that include sexual exploitation and labour exploitation, but also slavery and similar practices, the extraction of organs, etc. Sometimes there is some confusion between the crime of human trafficking and other crimes, so it is necessary to analyse it from different perspectives in order to guarantee the protection of the victims. In this study a review has been made from different perspectives: approach to the centralization of the victim, approach to criminalization of crime or fight against crime, gender approach and approach based on human rights. The study has been focused on the last perspective because of the serious violation of human rights that affects in all aspects the victims' legal sphere.
\end{abstract}

Key Words: Human trafficking; human rights; crime, slavery; exploitation. 


\section{INTRODUCCIÓN}

La trata de personas engloba la captación, el traslado y el aislamiento de seres humanos para obtener beneficios a su costa a través de la explotación. En todas sus variantes produce numerosas ganancias a las redes de explotadores, grandes secuelas en las víctimas y constituye enormes costes para la sociedad (OEA, 2005).

Este fenómeno delictivo se desarrolla en un contexto social, económico y político que se basa en las desigualdades y supone una constante violación de los derechos humanos. Para poder estudiarlo, hay que encuadrarlo dentro del marco de la delincuencia organizada transnacional relacionada con la migración y la vulnerabilidad de los países de origen de la mayoría de las víctimas (Magaña, 2017).

Combatir este delito es una de las prioridades de la Unión Europea y los países que la forman ya que este fenómeno es una de las mayores preocupaciones del siglo XXI por su gran impacto social (OPUE, 2013).

La amenaza que produce el delito de trata de personas, como el resto de delincuencia organizada, es a nivel internacional poniendo en peligro no solo a los países más vulnerables, sino al mundo entero. Ningún país puede luchar en solitario contra los problemas que este tipo de delitos acarrean, cada vez resulta más obvio que hay que buscar una cooperación internacional. Uno de los principales problemas para aproximarnos a este fenómeno es la dificultad que hay para acceder a fuentes fiables para investigar la delincuencia organizada, la documentación existente es muy poca y en gran parte no se corresponde con la realidad. Además, surgen otras dificultades como la relación de la delincuencia organizada con la corrupción y el clientelismo o con el mundo empresarial (Sansó-Rubert, 2005).

Existen distintos enfoques desde los que se aborda la lucha contra la trata de personas propuestos por las Naciones Unidas, que serán analizados en este trabajo, pero se ha basado en la perspectiva basada en los derechos humanos, que se centra en la idea universal a partir de la cual se desarrollan una serie de derechos que posee cualquier persona de cualquier lugar del mundo (Jaimes, Parra \& Aceros, 2017).

Se pretende conocer cuáles son las características del delito de trata de personas, cuáles son las herramientas empleadas en la lucha contra la trata de personas y si la perspectiva basada en los derechos humanos es la más idónea.

El objetivo general es realizar una revisión bibliográfica acerca de la trata de seres humanos como tipo penal y como fenómeno, su evolución en los últimos años y las perspectivas desde las que se estudia, centrándose en la perspectiva basada en los Derechos Humanos. 
Los objetivos específicos, en relación con el objetivo general son los siguientes:

1. Conocer más el delito de trata de seres humanos.

2. Analizar la legislación en materia de prevención y sanción del delito, que incluye la tipificación del hecho en el Código Penal, los medios empleados para la comisión del delito y el fin de la explotación.

3. Analizar las perspectivas criminocéntrica, victimocéntrica, de género y de derechos humanos.

4. Construir una teoría que dé validez la necesariedad de la perspectiva de derechos humanos.

\section{MÉTODOS}

\section{ESTRATEGIA DE BÚSQUEDA}

Para llevar a cabo este estudio, se ha realizado una revisión sistemática de documentos y artículos publicados para encontrar toda la información necesaria. Este procedimiento se ha realizado en dos etapas: búsqueda de bibliografía y búsqueda basada en las referencias encontradas.

En la primera etapa de búsqueda, se han utilizado bases de datos dedicadas a temas jurídicos como Aranzadi Instituciones, El Derecho, EUR-Lex, Web of Science, Academic Search Comlete, Scorpus, SAGE Humanities and Social Science (HSS) Package y Google Scholar. En ellas se han buscado documentos y artículos publicados sobre el tema y leyes, convenciones y protocolos dedicados al delito. Se realizó la búsqueda a través de las palabras clave "Trata de Personas", "Derechos Humanos", "Delincuencia organizada" y sus correspondientes términos traducidos al inglés.

Por otro lado, se buscaron datos publicados por el Ministerio del Interior y el Ministerio del Exterior para conocer las cifras en España. También se hizo una revisión de documentos publicados por agencias u organizaciones dependientes de la Organización de las Naciones Unidas (ONU) como la Organización Internacional de Migraciones (OIM), Alto Comisionado de las Naciones Unidas para los Refugiados (ACNUR) y el Fondo de las Naciones Unidas para la Infancia (UNICEF). Por último, se investigó a partir de documentos de Organizaciones No Gubernamentales relacionadas con el tema como la Asociación para la Prevención, Reinserción y Atención a la Mujer Prostituida (APRAMP) o Proyecto Esperanza.

Tras hacer la selección de documentos útiles, se pasó a analizar sus referencias bibliográficas. Se hizo una búsqueda de los títulos que contenían las palabras "Trata de Personas" en las bases de datos antes mencionadas. 


\section{CRITERIOS DE EXCLUSIÓN Y DE INCLUSIÓN}

Una vez se finalizó la revisión sistemática de documentos, se hizo la selección de los que interesaban para la realización del trabajo siguiendo como criterio de inclusión aquellos documentos que estaban actualizados y aquellos que hablaban del delito desde las perspectivas mencionadas. Se excluyeron aquellos documentos que trataban el delito de manera confusa, mezclándolo mucho con otros tipos penales y aquellos documentos que no eran de fuentes oficiales.

\section{ANÁLISIS DE DATOS}

Al realizar la búsqueda inicial de documentos se obtuvieron 62 documentos. Tras la aplicación de los criterios de exclusión, se descartaron 11 documentos por no cumplirlos, quedando un total de 51 documentos. Para saber si los documentos eran de utilidad se ha realizado una lectura del abstract primero para después pasar a hacer una lectura completa.

Tabla 1. Documentos para el análisis de datos

\begin{tabular}{|c|c|c|}
\hline Tipo de documento & Fuente & Número \\
\hline \multirow{2}{*}{ Artículos de revistas } & Bases de datos online & 24 \\
\cline { 2 - 3 } & Biblioteca & 1 \\
\hline $\begin{array}{c}\text { Artículos de revistas } \\
\text { electrónicas }\end{array}$ & Bases de datos online & 3 \\
\hline Libros & & 2 \\
\hline \multirow{2}{*}{ Informes } & ONG & 2 \\
\cline { 2 - 3 } & Ministerio & 5 \\
\cline { 2 - 3 } & ONU & 5 \\
\hline \multirow{2}{*}{$\begin{array}{c}\text { Leyes, convenciones y } \\
\text { protocolos }\end{array}$} & UE & 1 \\
\hline Mensaje en un blog & Nacionales & 1 \\
\hline
\end{tabular}

Fuente: elaboración propia. 


\section{MARCO JURÍDICO}

\section{MARCO JURÍDICO INTERNACIONAL}

Desde principios del siglo XX, se ha trabajado para reforzar la lucha contra la trata de personas, sobre todo desde la creación de la ONU y las agencias especializadas como la OIM, la Organización Internacional del Trabajo (OIT) o la Oficina de las Naciones Unidas contra la Droga y el Delito (ONUDC). Desde el momento en el que se asumió la gravedad de la situación, se hizo la distinción entre "trata laboral" y "trata sexual". En cuanto a la primera modalidad, uno de los primeros instrumentos que se publicaron fue la Convención sobre la Esclavitud en Ginebra (Sociedad de Naciones, 1926) en el que se define la esclavitud como: "el estado o condición de un individuo sobre el cual se ejercitan los atributos del derecho de propiedad o de alguno de ellos". Con respecto a la segunda modalidad, se inició la lucha con la aprobación del Acuerdo Internacional Para la Represión de la Trata de Blancas (Sociedad de Naciones, 1904), aunque no resultó muy eficaz (Daunis, 2013).

A partir de ahí, se empezaron a adaptar los sistemas legislativos de las diferentes naciones en relación con lo establecido internacionalmente. En estos instrumentos se evidencia que la responsabilidad es internacional, por lo que la respuesta también debe de serlo. Además, según los artículos 26 y 27 de la Convención de Viena sobre el Derecho de los Tratados, los Estados no pueden poner por encima del derecho internacional el derecho interno para no llevar a cabo las obligaciones impuestas (UNODC, 2009).

Entre los instrumentos internacionales aprobados en el marco de la ONU, relacionados con la lucha contra la trata de personas, destacan los siguientes (García, 2008):

1. La Declaración Universal de los Derechos Humanos (Asamblea General de las Naciones Unidas, 1948). La trata de personas es un delito que afecta directamente a los derechos fundamentales de las víctimas y en este instrumento proporciona lo fundamental en materia de derechos humanos.

2. Convención internacional contra la trata de personas y la explotación de la prostitución ajena de Naciones Unidas (ONU, 1949). Fue creado para la lucha contra la explotación sexual.

3. Convenio sobre la eliminación de todas las formas de violencia contra la mujer (ONU, 1979). En el artículo 6 de la Parte I, se hace referencia al compromiso que hace falta por parte de los Estados para eliminar la trata y la explotación sexual de la mujer.

4. Resolución de las Naciones Unidas sobre la protección de los menores frente a la trata y la explotación sexual (ONU, 1989). En este documento aparecen las medidas que hay que adoptar para impedir el secuestro, la venta o la trata de menores con cualquier fin. 
5. Convención sobre los Derechos del Niño (ONU, 1989). Establece que todos los niños nacen con los mismos derechos sin excepción e inicia la protección de los menores de edad ante la explotación económica y cualquier trabajo que interrumpa su desarrollo o educación. Según este instrumento, los Estados deben tomar las medidas necesarias para evitar el secuestro, la venta o la trata de niños para cualquier fin y deben protegerles contra todo tipo de explotación o abuso.

6. Protocolo para Prevenir, Reprimir y Sancionar la Trata de Personas, Especialmente Mujeres y Niños, que complementa la Convención de las Naciones Unidas Contra la Delincuencia Organizada Transnacional (Protocolo de Palermo) (ONU, 2000). De los instrumentos relacionados con el delito de trata de personas, éste es uno de los más importantes. En él se define la trata de personas para poder identificar a las víctimas de este delito y se establecen las normas necesarias pare prevenir, perseguir y enjuiciar a los victimarios.

7. Principios y Directrices recomendados sobre los Derechos Humanos y Trata de Personas (ACNUDH ACNUR, 2002). Este documento ha sido desarrollado para la prevención y la protección de las víctimas de trata a través de la perspectiva de derechos humanos.

8. Resolución de la Asamblea General (ONU, 2011). Se presenta un Plan de Acción Mundial para luchar contra el delito de trata de personas promoviendo el cumplimiento de lo propuesto anteriormente, dar ayuda a los Estados para que refuercen su normativa, aumentar el trabajo con las organizaciones no gubernamentales dedicadas al tema e implantar un enfoque basado en los derechos humanos.

\section{MARCO JURÍDICO DE LA UNIÓN EUROPEA}

El Derecho de la Unión Europea no es Derecho internacional, pero igualmente España se ve vinculada a él ya que ha de aplicar directamente algunos de los supuestos (Villacampa, 2011).

Desde la Unión Europea, se han creado a lo largo de los años distintas herramientas para condicionar la intervención comunitaria en política migratoria. Es en 2002, con la aprobación de Decisión Marco 2002/629, del Consejo relativo a la lucha contra la trata de seres humanos, cuando se puede empezar a hablar de intervención en materia de trata de seres humanos. En 2005 se aprueba el Convenio del Consejo de Europa sobre la lucha contra la trata de seres humanos, también conocido como Convenio de Varsovia, donde se define por primera vez el término "víctima de trata". En 2011 se sustituye la Decisión Marco 2002/629 al ser aprobada por el Parlamento Europeo y el Consejo la Directiva 2011/36/UE 
(DUE'2011), relativa a la prevención y lucha contra la trata de seres humanos y a la protección de las víctimas (Daunis, 2013).

\section{CÓDIGO PENAL ESPAÑOL}

\subsection{Antecedentes}

Desde la reforma de la Ley Orgánica 5/2010, de 22 de julio, por la que se modifica la Ley Orgánica 10/1995, de 23 de noviembre, del Código Penal (en adelante $\mathrm{CP})$, se incluye el Título VII bis, "De la trata de seres humanos" en el Libro II del mismo. Este Título está formado por un único artículo, el 177 bis del CP, en el que se tipifica la trata de seres humanos.

Esta reforma se realizó tras los compromisos internacionales que había asumido España. Hasta ese momento, se había incluido la tipificación de esas conductas de manera autónoma, por ejemplo, a través del artículo 188.2 del CP incluido en 1999 y ya eliminado, contra la trata para la explotación sexual. Tras la asunción de obligaciones internacionales por parte de nuestro país y con el propósito de darles cumplimiento se procedió a una tipificación autónoma del delito de trata d seres humanos y tráfico ilícito de inmigrantes (Villacampa, 2011).

\subsection{Tipo penal}

El artículo 177 bis del CP (Ley 10/1995) reza:

"1. Será castigado con la pena de cinco a ocho años de prisión como reo de trata de seres humanos el que, sea en territorio español, sea desde España, en tránsito o con destino a ella, empleando violencia, intimidación o engaño, o abusando de una situación de superioridad o de necesidad o de vulnerabilidad de la víctima nacional o extranjera, o mediante la entrega o recepción de pagos o beneficios para lograr el consentimiento de la persona que poseyera el control sobre la víctima, la captare, transportare, trasladare, acogiere, o recibiere, incluido el intercambio o transferencia de control sobre esas personas, con cualquiera de las finalidades siguientes:

a) La imposición de trabajo o de servicios forzados, la esclavitud o prácticas similares a la esclavitud, a la servidumbre o a la mendicidad.

b) La explotación sexual, incluyendo la pornografía.

c) La explotación para realizar actividades delictivas.

d) La extracción de sus órganos corporales.

e) La celebración de matrimonios forzados.

Existe una situación de necesidad o vulnerabilidad cuando la persona en cuestión no tiene otra alternativa, real o aceptable, que someterse al abuso. 
2. Aun cuando no se recurra a ninguno de los medios enunciados en el apartado anterior, se considerará trata de seres humanos cualquiera de las acciones indicadas en el apartado anterior cuando se llevare a cabo respecto de menores de edad con fines de explotación.

3. El consentimiento de una víctima de trata de seres humanos será irrelevante cuando se haya recurrido a alguno de los medios indicados en el apartado primero de este artículo".

\section{EL DELITO DE TRATA DE PERSONAS}

\section{APROXIMACIÓN CONCEPTUAL}

La trata de personas es definida, según el artículo 3 del Protocolo para Prevenir, Reprimir y Sancionar la Trata de Personas, Especialmente Mujeres y Niños, que complementa la Convención de las Naciones Unidas Contra la Delincuencia Organizada Transnacional (ONU, 2000) como:

Por "trata de personas" se entenderá la captación, el transporte, el traslado, la acogida o la recepción de personas, recurriendo a la amenaza o al uso de la fuerza u otras formas de coacción, al rapto, al fraude, al engaño, al abuso de poder o de una situación de vulnerabilidad o a la concesión o recepción de pagos o beneficios para obtener el consentimiento de una persona que tenga autoridad sobre otra, con fines de explotación. Esa explotación incluirá, como mínimo, la explotación de la prostitución ajena u otras formas de explotación sexual, los trabajos o servicios forzados, la esclavitud o las prácticas análogas a la esclavitud, la servidumbre o la extracción de órganos.

El término "trata de personas" surge a raíz del término "trata de blancas". El término "trata de blancas" se origina en el siglo XIX para diferenciarlo de la trata de personas de raza negra, que en ese momento era legal. Es a mediados del siglo XX cuando el término evoluciona a "trata de personas", englobando las víctimas sin hacer ningún tipo de discriminación por raza, sexo o edad. La trata de personas tiene como fin tratar a una persona como una cosa, como si fuera una mercancía (Carrasco, 2014).

Según Villacampa (2011), la trata de personas tiene algunos aspectos relacionados con la esclavitud tradicional, pero se diferencia de ella en varios puntos. Anteriormente, los esclavos pertenecían al dueño, por lo que éste debía cuidarle para que le saliera rentable su inversión, ya que la relación que se establecía era a largo plazo. En la actualidad, la víctima no es propiedad del victimario y la relación que se establece es mucho más reducida en el tiempo, por lo que no se ven en la obligación de cuidarlas y mantenerlas. Además, mientras que antes la etnia de la víctima era muy importante, ahora ya no lo es tanto. 
Los victimarios seleccionan a sus víctimas y les prometen mejores condiciones de vida. Engañan a la víctima y, en ocasiones, engañan también a la familia para sacarla de su entorno y la aíslan (Reunes, 2018). Los grupos de delincuencia organizada les ofrecen un trabajo, oportunidades de educación, mejoras en su nivel económico, aumento del nivel de vida, etc. (UNDOC, 2009).

Este delito comienza con la captación de las víctimas, que después son trasladadas dentro o fuera del país y finaliza con la explotación (Torres, 2016). Un elemento clave es la explotación, pero abarca distintos tipos entre los que se encuentran la explotación sexual, la explotación laboral, la esclavitud y la extracción y el tráfico de órganos (ONU, 2000).

En todas sus variantes, la trata de personas proporciona grandes cantidades de dinero a las redes de explotación, solo siendo superadas por el tráfico de drogas y el tráfico de armas (Torres, 2016). Las redes son cada vez más fuertes y la demanda cada vez es más insistente colocando el delito de trata de personas el tercer delito a nivel mundial de delincuencia organizada (Henríquez-Cáceres y Vargas-Vargas, 2018).

\section{ELEMENTOS DEL DELITO DE TRATA DE PERSONAS}

La trata de personas fue definida por primera vez en el Protocolo para Prevenir, Reprimir y Sancionar la Trata de Personas, Especialmente Mujeres y Niños o Protocolo de Palermo y se suele resumir haciendo referencia a los elementos principales de la definición (FEI, 2011):

a) Acción: engloba todos los verbos que integran la conducta típica: captar, transportar, trasladar, acoger o recibir. El artículo 177 bis del CP emplea verbos típicos similares a los que se emplean en el Protocolo de Palermo (ONU, 2010) para definir la acción típica.

$\mathrm{Al}$ incluir las figuras de captar, transportar, trasladar, acoger y recibir no solo estaría prohibido el desplazamiento de la víctima, sino también las acciones anteriores y posteriores. Podría dividirse en tres etapas: $1^{\circ}$ captación, que se produce manipulando a la víctima a través de una oferta falsa de trabajo que no existe o que no cumple con las condiciones pactadas; $2^{\circ}$ transportar y trasladar, que puede ser tanto dentro como fuera del propio país; y $3^{\circ}$ acoger o recibir en el lugar en el que se va a realizar la explotación de la víctima (Daunis, 2013).

b) Medios: serían los mecanismos de sometimiento que emplean los victimarios para que las víctimas cumplan con sus órdenes. Entre ellos se encuentran la violencia, intimidación, engaño o abuso de una situación de superioridad o de necesidad o de vulnerabilidad y el intercambio o traspaso. 
Como dice el artículo 177.2 bis del CP, en el caso de que la víctima sea menor de edad no hará falta que exista este elemento.

Según los medios empleados, podemos distinguir hasta tres modalidades de trata de personas entre las que se encuentran: $1^{\circ}$ la trata forzada, cuando se realiza a través de violencia o intimidación; $2^{2}$ la trata fraudulenta, cuando se hace a través del engaño; y 3 o la trata abusiva, cuando es aprovechando una situación de superioridad o una situación de vulnerabilidad y necesidad de la víctima. La primera modalidad, aunque ha sido una de las más protagonistas, actualmente no se suele dar (Daunis, 2013).

c) Fines: todo tipo de actividades que las víctimas se ven forzadas a realizar como la explotación sexual, la explotación laboral, esclavitud y prácticas similares, extracción de órganos, explotación para llevar a cabo delitos y la celebración de matrimonios forzados.

El fin de la trata de personas es la explotación de las víctimas en cualquier modalidad. Lo que se busca fundamentalmente es, a través de la realización de determinadas actividades, la apropiación del beneficio obtenido de la víctima. Dentro de los fines del delito, podemos encontrar distintas formas de trata (Villacampa, 2011):

- La trata para la explotación laboral. Las víctimas son obligadas a realizar una actividad que produzca beneficio; a ser esclavos convirtiéndose en objeto y privándoles de todos sus derechos o formas análogas a la esclavitud, a la servidumbre o a la mendicidad (Art. 177.1.a bis del CP) y a cometer actos delictivos (Art, 177.1.c bis del CP).

- La trata para la explotación sexual (Art. 177.1.b bis del CP). Esta forma de trata ha sido durante muchos años la más investigada y según las investigaciones de las principales organizaciones que luchan contra la trata, ésta es la principal finalidad por la que se lleva a cabo el delito (Daunis, 2013).

- Otras formas de trata. Estas modalidades no encajarían en los dos grandes bloques de formas de trata explicados anteriormente, pero están tipificados en el CP. Son la extracción de órganos para el tráfico ilegal (Art. 177.1.d bis del CP) y obligar a la víctima a celebrar un matrimonio forzado (Art. 177.1.e bis del CP). Según Villacampa (2011), aquí podrían incluirse otras finalidades como el empleo de niños en conflictos armados y el supuesto de adopciones ilegales.

\section{DIFERENCIA CON EL DELITO DE TRÁFICO ILÍCITO DE PERSONAS}

Para poder entender el fenómeno de trata de personas es importante tener en cuenta su naturaleza transnacional, junto con las causas económicas y sociales 
que producen la necesidad de migración: desigualdad en la distribución económica, falta de acceso a la educación y al empleo, disminución de las vías legales para los traslados internacionales en búsqueda de empleo. Todo ello es lo que ha contribuido al aumento del tráfico ilegal de inmigrantes y de la trata de personas (Carrasco, 2014).

Tiene mucha importancia diferenciar entre la trata de personas y el tráfico ilícito de inmigrantes porque los elementos constitutivos de delito son diferentes y porque la respuesta ante el delito depende del tipo penal al que las autoridades se enfrenten (UNDOC, 2009). Durante mucho tiempo ha existido una cierta confusión entre los términos "tráfico ilícito de migrantes" y "trata de personas" hasta que en el año 2000 la Convención de las Naciones Unidas contra la Delincuencia Organizada Transnacional y Protocolos Complementarios se definieron (Carrasco, 2014).

Según el artículo 3 del Protocolo contra el Tráfico Ilícito por Tierra, Mar y Aire que complementa la Convención de las Naciones Unidas contra la Delincuencia Organizada Transnacional, se establece que:

"Por "tráfico ilícito de migrantes" se entenderá la facilitación de la entrada ilegal de una persona en un Estado Parte del cual dicha persona no sea nacional o residente permanente con el fin de obtener directa o indirectamente un beneficio financiero u otro beneficio de orden material.

Ambos delitos son diferentes, pero pretenden castigar situaciones que son muy similares. La diferencia principal entre los dos delitos es que en el delito de trata de personas el fin es obtener beneficios económicos a partir de la explotación de la víctima mientras que en el delito de tráfico ilícito de personas los beneficios económicos se obtienen a partir del traslado de una persona de un país a otro de manera ilegal (Carrasco, 2014).

Las principales diferencias entre ambos delitos son (García, 2008):

- Fuente del beneficio. En el caso del delito de tráfico ilegal de migrantes, los criminales buscan trasladar a la persona de un lugar a otro y ganar dinero con ello exigiendo el dinero por adelantado. Sin embargo, en el caso del delito de trata, los victimarios pretenden explotar a la víctima creando una deuda entre ella y los traficantes.

- Explotación. Mientras que el delito de tráfico ilícito finaliza cuando llegan los inmigrantes al país, el delito de trata de personas implica la explotación constante de las víctimas una vez se ha llegado al lugar.

- Consentimiento. En el caso del tráfico ilícito, las personas dan su consentimiento, aunque el traslado sea bajo condiciones peligrosas. Sin embargo, las víctimas de trata, aunque hubieran consentido, no se considera como tal porque ha sido bajo coacción, engaño o abuso de los victimarios. 
- Transnacionalidad. En el caso de la trata de personas, al contrario que en el caso del tráfico ilícito, no es necesario que las víctimas sean trasladadas a un país diferente, pueden ser desplazadas dentro del mismo.

- Regularidad del traslado. En el caso de la trata de personas, las víctimas pueden cruzar las fronteras legalmente. Según un estudio de la OIM (2018), la mayoría de las víctimas entran por los puntos fronterizos de manera oficial.

- Bien jurídico protegido. El bien jurídico protegido con el tipo penal del tráfico de personas es la "defensa de los intereses del Estado con el control de los flujos migratorios", en el caso de la trata, protege la dignidad y la libertad del sujeto pasivo.

Tabla 2. Comparación entre el delito de trata de personas y el delito de tráfico ilícito de migrantes

\begin{tabular}{|c|c|c|}
\hline Elemento & Trata de personas & Tráfico ilícito de migrantes \\
\hline Fuente del beneficio & Explotación & Económicos \\
\hline Explotación & Sí & No \\
\hline Consentimiento & No válido & Válido \\
\hline Transnacionalidad & No necesario & Necesario \\
\hline Traslado & Regular o irregular & Irregular \\
\hline Delito (bien jurídico) & Contra la persona & Contra el Estado \\
\hline
\end{tabular}

Fuente: García (2018).

\section{LA TRATA DE PERSONAS EN ESPAÑA}

Para hablar de la situación del fenómeno de la trata de personas en España, es esencial hablar de las cifras estimadas por las distintas instituciones, este trabajo se va a centrar en los informes del Ministerio del Interior y del Ministerio Fiscal.

Por un lado, según el Centro de Inteligencia contra el Terrorismo y el Crimen Organizado (CITCO) perteneciente al Ministerio del Interior, durante el año 2017 habría un total de 10.111 personas en riesgo, de las cuales el 99\% eran mujeres y 12.807 personas identificadas (Ministerio del Interior, 2018).

Por otro lado, según la Memoria de la Fiscalía General del Estado, durante el año 2017 se identificaron un total de 465 víctimas de trata, de las cuales casi el 90\% eran mujeres (Ministerio Fiscal, 2018). 


\section{PERSPECTIVAS DE LUCHA CONTRA LA TRATA DE PERSONAS}

La trata de personas es una grave vulneración a los derechos humanos, por lo que los Estados deben garantizar la protección integral de las víctimas. A pesar de que existe una clara relación entre el delito de trata de personas y los derechos humanos, por la complejidad del término y del delito, la lucha contra la trata está enfocada desde distintos prismas (Reyes, Vargas \& Aceros, 2017).

Para el abordaje del fenómeno y la protección de las víctimas existen distintas perspectivas, fundamentalmente son la perspectiva basada en los derechos humanos, la perspectiva de género, la perspectiva de criminalización del delito o de lucha contra la delincuencia y la perspectiva centrada en la víctima o victimocéntrica.

\section{PERSPECTIVA BASADA EN LOS DERECHOS HUMANOS}

Actualmente se cree que la mejor manera de combatir la trata de personas de manera eficaz es abarcando todas las modalidades y las fases desde una perspectiva de derechos humanos y obligar a los gobiernos a tener la responsabilidad de protegerlos (Jiménez, 2007).

La perspectiva o enfoque basado en los derechos humanos (EBDH) es una propuesta que pretende que las herramientas elaboradas por las distintas instituciones de todos los estados se centren en garantizar la protección de los Derechos Humanos de todas las personas. De esta manera, los estados no solo apuntan las necesidades de la población, también reconocen la obligación que tienen de satisfacerlas. Aporta a las víctimas herramientas para poder defenderse de las violaciones de sus derechos (Willat, 2006). Pretende ser un marco teórico internacional a partir del cual se orienten las políticas de desarrollo y que sirva de pauta para marcar las obligaciones de los gobiernos con respecto a la asistencia internacional tanto en países donantes como receptores (Abramovich, 2006).

Hoy en día ésta es la perspectiva de lucha contra la trata más importante porque relaciona directamente el fenómeno de la trata con la vulneración de los derechos humanos de las víctimas. Algunos de los instrumentos aprobados por las Naciones Unidas y por la Organización Internacional del Trabajo mencionados anteriormente se centran en la protección de los derechos humanos vulnerados, por lo que ya tiene un largo recorrido en lo que a Derecho internacional se refiere (Rodríguez, 2017). De esta manera, la perspectiva criminocéntrica en la que se basaban las herramientas inicialmente, se ha ido quedando atrás al ya no abordar este delito desde un enfoque trafiquista para centrarse en la grave vulneración de los derechos humanos que es (Daunis, 2013). 
Las herramientas que se encuentran en el marco de la perspectiva basada en los derechos humanos no se centran tanto en la lucha contra la trata como un delito, sino que enfoca la lucha desde la protección de las víctimas. Por ello, los distintos organismos de lucha contra la trata, incluida la Unión Europea, se replantean acercarse más a este paradigma (Villacampa, 2011).

Según Maus (2018), casi cualquier derecho humano es susceptible de ser vulnerado por la trata de personas, pero algunos de estos derechos son más fáciles de analizar, lo que facilita a los Estados ser conscientes de las violaciones a los derechos humanos de las víctimas de este delito y su magnitud y afectación. Entre ellos se encuentran:

1. Derecho a la dignidad. Según el artículo 1 de la Declaración de los Derechos Humanos (Asamblea General de las Naciones Unidas, 1948) "Todos los seres humanos nacen libres e iguales en dignidad y derechos y, dotados como están de razón y conciencia, deben comportarse fraternalmente los unos con los otros".

La dignidad es un concepto jurídico protegido por numerosos instrumentos internacionales y leyes que debe ser respetado como base de todos los derechos (Maus, 2014). El delito de trata de personas es incompatible con el respeto de la dignidad de las personas, poniendo en peligro el bienestar de la persona, la familia e incluso de la sociedad (Convención para la Represión de la Trata de Personas y de la Explotación de la Prostitución Ajena).

2. Derecho a la vida. Según el artículo 3 de la Declaración Universal de los Derechos Humanos (Asamblea General de las Naciones Unidas, 1948) "Todo individuo tiene derecho a la vida, a la libertad y a la seguridad de su persona". Es un derecho que no puede ser vulnerado en épocas de guerra, peligro público u otras amenazas, siendo los Estados responsables de crear condiciones para evitar ataques hacia él.

3. Derecho a no ser sometido a trata y explotación. Según el artículo 4 de la Declaración Universal de los Derechos Humanos (Asamblea General de las Naciones Unidas, 1948) "Nadie estará sometido a esclavitud ni a servidumbre; la esclavitud y la trata de esclavos están prohibidas en todas sus formas".

4. Derecho a la debida procuración de justicia. Según el artículo 10 de la Declaración Universal de los Derechos Humanos (Asamblea General de las Naciones Unidas, 1948) "Toda persona tiene derecho, en condiciones de plena igualdad, a ser oída públicamente y con justicia por un tribunal independiente e imparcial, para la determinación de sus derechos y obligaciones o para el examen de cualquier acusación contra ella en materia penal". Este derecho se compone de diferentes elementos como la investigación del delito, la identificación de las víctimas, persecución adecuada, garantía de no repetición, etc. La mayoría de los casos no son conocidos por las autoridades constituyendo la cifra negra no concretada. 


\section{PERSPECTIVA DE GÉNERO}

La trata principalmente es un asunto de género ya que, según datos de la ONUDC (ACNUR, 2017), un 71\% de las víctimas son mujeres y niñas, mientras que, en el caso de los traficantes, el 63\% son hombres. Se emplea el enfoque de género haciendo referencia al significado, las relaciones y las identidades formadas en torno a las diferencias de género.

Esta perspectiva permite que este fenómeno sea estudiado dependiendo de si la víctima es un hombre o una mujer, teniendo diferentes características en un caso y en otro. En cuanto a las similitudes, encontramos que en ambos casos destacan aquellas características que sitúan a una persona en una situación más vulnerable, como puede ser el nivel económico o cultural (Magaña, 2017).

Desde la perspectiva de género se permite analizar el delito de trata de personas comprendiendo las diferencias y desigualdades entre los géneros en una situación social concreta y en las relaciones de poder que sitúan a la mujer en el lado de la oferta y al hombre en el lugar de la demanda. Para entender este enfoque, hay que hablar primero de la discriminación que existe hacia las mujeres que, según la Convención sobre la eliminación de todas las formas de discriminación contra la mujer (1979), es "toda distinción, exclusión o restricción basada en el sexo, que tenga por objeto o resultado menoscabar o anular el reconocimiento, goce o ejercicio por la mujer, independientemente de su estado civil, sobre la base de la igualdad del hombre y la mujer, de los derechos humanos y las libertades fundamentales en las esferas política, económica, social, cultural y civil o en cualquier otra esfera”. Esta discriminación sitúa a las mujeres en una situación de exclusión y vulnerabilidad superior (Castellanos y Ranea, 2013).

Por otro lado, encontramos diferencias como la situación que generan los estereotipos de género proporcionando formas de abuso. Los criminales no utilizan las mismas técnicas de reclutamiento para hombres y para mujeres. Hay que tener en cuenta estas diferencias para que los procesos de detección de víctimas y de grupos criminales organizados dedicados a la trata sean más eficaces. También hay que ceñirse a las necesidades concretas que puedan tener tanto hombres como mujeres para evitar añadir tensión a la situación de la víctima (Magaña, 2017).

\section{PERSPECTIVA CENTRADA EN LA VÍCTIMA DEL DELITO O VICTIMOCÉNTRICO}

El instrumento que da paso a la perspectiva victimocéntrica es el Protocolo de Palermo, que se centra no solo en equiparar las medidas legislativas de los distintos países, también pretende influir en la protección de las víctimas y la prevención del delito (Villacampa, 2011). Según Villacampa (2011b), el aspecto 
central de esta perspectiva es la prevención del fenómeno y para ello hay que centrarse en las causas. Para ello, hay que poner el foco de atención en las políticas económicas que provocan flujos migratorios irregulares y que colocan a un sector de la población en una situación de vulnerabilidad.

Para luchar contra el delito de trata de personas, es importante que tanto las víctimas, como los profesionales y los Estados miembros, estén informados sobre los derechos de las víctimas que recoge la legislación de la Unión Europea. Entre ellos podemos encontrar los siguientes (Oficina de Publicaciones de la Unión Europea, 2013):

1. Asistencia y apoyo.

2. Protección antes, durante y después del proceso penal.

3. Indemnización.

4. Integración y derechos laborales.

5. Período de reflexión y permiso de residencia para las víctimas que sean nacionales de terceros países.

6. Retorno.

En el artículo 12 de la Directiva 2011/36/UE se establecen las medidas de protección de las víctimas de trata de seres humanos principalmente centrándose en evitar casos de victimización secundaria. Además, aclara que las víctimas de este delito deben recibir un tratamiento individualizado según sus necesidades (Villacampa, 2011b).

\section{PERSPECTIVA DE CRIMINALIZACIÓN DEL DELITO O DE LUCHA CONTRA LA DELINCUENCIA}

Desde la perspectiva criminocéntrica, la lucha contra la trata de personas se realiza casi exclusivamente desde el derecho penal. Aborda solo parcialmente el problema centrándose en la parte de perseguir el delito y deja fuera la prevención y la protección de las víctimas (Villacampa, 2011b).

Las políticas y marcos normativos se centran en reconocer la responsabilidad legal de los victimarios implicados en casos de trata de personas. Esta perspectiva se centra en el delito de trata de personas como el incumplimiento de la norma establecida de una manera tan grave que el autor o los autores del delito deben ser sancionados por ello (Reyes et al., 2017). Este enfoque se relaciona más con los primeros instrumentos internacionales de lucha contra la trata como las convenciones aprobadas para la lucha contra la trata de blancas durante el siglo XX por la Sociedad de Naciones (Villacampa, 2011).

La perspectiva criminocéntrica ve la trata de personas como un delito que pertenece a la delincuencia organizada al que se debe dar una respuesta 
principalmente punitiva. Se han creado los tipos penales específicos de la trata y se han ido ampliando para conseguir abarcar todas las formas en las que se puede dar. Al mismo tiempo se han ido estableciendo las penas privativas de libertad que responden de manera más proporcionada a la gravedad de la situación (Rodríguez, 2017).

Mientras que a nivel internacional los instrumentos han ido evolucionando desde una perspectiva totalmente criminocéntrica a una perspectiva victimocéntrica que tiene en cuenta los derechos vulnerados de las víctimas de trata y su recuperación, en la Unión Europea es puramente punitivo (Villacampa, 2011).

Al mismo tiempo que se han desarrollado las herramientas para la lucha contra la trata centradas en una perspectiva criminocéntrica, progresivamente el panorama se ha ido centrando cada vez más en la víctima. La cuestión va más allá de dar una respuesta penal a las organizaciones, también recoge los derechos fundamentales de las víctimas que son vulnerados por ellos atendiendo a su protección y reparación (Rodríguez, 2017).

\section{CONCLUSIÓN}

Como ha sido expuesto en el trabajo, el delito de trata de personas constituye una clara violación de los derechos humanos de las víctimas. El fin es en todos casos la explotación, de diversas formas, de la persona para la obtención de beneficios económicos. Existen numerosos instrumentos para combatir este crimen, tanto internacionales como nacionales, entre los que se encuentra el más importante, el Protocolo para Prevenir, Reprimir y Sancionar la Trata de Personas, Especialmente Mujeres y Niños, que complementa la Convención de las Naciones Unidas Contra la Delincuencia Organizada Transnacional (Protocolo de Palermo) (ONU, 2000), en el que se define el delito y se establecen las directrices que tienen que seguir los Estados para crear los instrumentos necesarios para acabar con este delito y las organizaciones.

El delito de trata puede verse relacionado con otros conceptos tales como la esclavitud o la explotación. La diferencia es que el fenómeno de la trata no se centra exclusivamente en la etapa final y más duradera en el tiempo, que es la explotación de la víctima para la obtención de algún beneficio, también recoge el paso de una situación en la que la víctima no se ve sometida a una situación en la que sí, es un proceso (Villacampa, 2011). Este delito es consumado desde el momento en el que la víctima ha perdido la libertad de decidir por sí misma, no hace falta que se dé la fase de explotación ya que se considera consumado desde la fase de la captación (Daunis, 2011). 
Es un delito que también podría parecer estar vinculado con el delito de tráfico ilícito de personas, tipificado en el artículo 318 bis del Título XV, "Delitos contra los derechos de los ciudadanos extranjeros" del CP (Ley 10/1995), porque en muchos casos conlleva el traslado de la víctima desde su país de nacimiento a el país en el que se va a dar la explotación. Hasta la reforma de la LO 5/2010 que introduce el Título VII bis del Libro II, "De la trata de seres humanos", en el CP (Ley 10/1995), éste no era un delito autónomo y no se diferenciaba del de tráfico ilícito de personas. Esto fue un gran avance en la lucha contra el fenómeno de trata de personas en España.

Los datos encontrados sobre cifras de víctimas de trata de personas en España pueden resultar confusas al ser tan diferentes dependiendo del órgano del que venga la información. Mientras desde el Ministerio del Interior se estima que hay más de 10.000 víctimas potenciales, en el Ministerio Fiscal se identifican menos de 500 durante el año 2017. Esto muestra que el fenómeno de la trata tiene actualmente una gran magnitud que es muy difícil de estimar al encontrarnos ante un caso de cifra negra. Además, otro gran problema que se presenta es el de la identificación de las víctimas.

Entre las razones que hay para que se mantengan todavía en el siglo XXI este tipo de actividades se puede encontrar en primer lugar la poca legislación que hay acerca de la regulación de la relación entre el contratante y el trabajador, establecida por el sistema económico en el que nos basamos. Esta relación se caracteriza por el incumplimiento de los derechos del empleado favoreciendo que se dé una situación de explotación (Daunis, 2013). En segundo lugar, la globalización y el deseo de muchas personas de salir de una situación de vulnerabilidad en sus lugares de origen que los lleva a creer promesas de los victimarios que jamás son cumplidas. Y, por último, la gran demanda que hay en los países receptores de este tipo de servicios, que favorece que los grupos organizados se beneficien de esta situación y sigan manteniéndola.

Los instrumentos empleados en la lucha contra la trata se han construido desde distintas perspectivas que son la perspectiva de género, la perspectiva de criminalización del delito o de lucha contra la delincuencia, la perspectiva centrada en la víctima o victimocéntrica, y la perspectiva basada en los derechos humanos. El más completo es el último, centrado en los derechos humanos, ya que como se ha explicado antes, este delito afecta a casi cualquier derecho humano de las víctimas.

La perspectiva basada en los derechos humanos tiene cada vez más espacio dentro de la lucha contra el delito de trata de personas porque es capaz de combinar las dos perspectivas más comunes a lo largo de la historia, la perspectiva criminocéntrica y la perspectiva victimocéntrica. 


\section{BIBLIOGRAFÍA}

Abramovich, V. (2006). Una aproximación al enfoque de derechos en las estrategias y políticas de desarrollo. Revista de la cepal, 88 (4), 35-50.

Acién, E. \& Checa, F. (2011). La actualidad del abordaje de la trata de personas para la prostitución forzada en España. El Plan Integral y sus implicaciones para trabajadoras del sexo inmigradas. Gazeta de Antropología, 27 (1), 1-19.

ACNUR. (2017). Trata de personas: la esclavitud del siglo XXI. Disponible en: https://eacnur.org/es/actualidad/noticias/eventos/trata-de-personas-la-esclavitud-del-siglo-xxi (última consulta: 20 de noviembre de 2018).

Asamblea General de la ONU. (1948). Declaración Universal de los Derechos Humanos. París.

Blanco, C. \& Marinelli, C. (2017). Víctimas de trata de personas versus migrantes en situación irregular. Retos y lineamientos para la atención y protección de las víctimas de trata de personas extranjeras en el Perú. Revista de la Facultad de Derecho, 78, 173-198.

Blázquez-Vilaplana, B. (2017). La trata de personas con fines de explotación sexual en España: elementos para la reflexión. Revista Espiga, 16 (34), 183-196.

Carrasco, G. (2014). Tipo penal del delito de trata de personas. Alegatos, 28 (86), 71-96.

Castellanos, E. \& Ranea, B. (2013). Explotación sexual de mujeres. Investigación sobre prostitución y trata de mujeres.

Centro de Inteligencia contra el Terrorismo y el Crimen Organizado (CITCO) del Ministerio del Interior (2018). Balance 2017: Prevención y lucha contra la trata de seres humanos en España. Disponible en: http://www.interior.gob.es/ documents/10180/7146983/Balance_2017_Trata.pdf/153296b3-be9b-44be921d-0b034f772a76

Comisión Europea (2013). Los derechos de las víctimas de la trata de seres humanos en la Unión Europea. Disponible en: http://www.proyectoesperanza.org/ wp-content/uploads/2010/05/EU+rights+of+victims_ES.pdf

Daunis, A. (2013). El delito de Trata de Seres Humanos. Valencia: Tirant lo Blanch.

Fernández, J. (2018). Esclavitud, trata de personas y explotación: una perspectiva desde los derechos humanos. El Cotidiano, 209, 47-56.

Fiscalía General del Estado. Ministerio de Justicia (2017). Memoria elevada al Gobierno de S.M. presentada al inicio del año judicial por el Fiscal General del Estado. Disponible en: https://www.fiscal.es/fiscal/publico/ciudadano/documentos/memorias_fiscalia_general_estado

Flamtermesky, H. (2014). Mujer Frontera. Experiencia de investigación acción participativa feminista (IAPF) con mujeres víctimas de la trata de personas. Athenea Digital, 14 (4), 389-400. 
France Expertise Internationale (FEI). (2013). Directrices para la detección de víctimas de trata en Europa. Disponible en: http://www.violenciagenero.igualdad.mpr.gob.es/otrasFormas/trata/detectarla/pdf/ManualDirectricesDeteccionTSH.pdf

García, S. (2008). Inmigración ilegal y trata de personas en la Unión Europea: la desprotección de las víctimas. ReDCE, 10, 231-274.

García, S. (2010). La trata en España: Una interpretación de los Derechos Humanos en perspectiva de género. Dilemata, 4 (10), 45-64.

Henríquez-Cáceres, E. \& Vargas-Vargas, B. (2018). Formación e intervención contra la trata de personas: experiencias del Programa Agenda Joven. Revista Espiga, 17(35), 1-17. Doi: http://dx.doi.org/10.22458/re.v17i35.1756

Jaimes, J. R., Parra, J. V., \& Aceros, J. C. (2018). Análisis de las medidas de asistencia a víctimas de trata de personas en Colombia en perspectiva de derechos humanos. Opinión Jurídica, 17 (33), 99-122.

Jerade, M. (2011, septiembre). La trata de personas. Escrituraleatoria, 112-115.

Jiménez, W.G. (2007). El enfoque de los derechos humanos y las políticas públicas. Civilizar. Ciencias Sociales y Humanas, 7 (12), 31-46.

Ley Orgánica del Código Penal 10/1995, de 30 de marzo de 2015, Boletín Oficial del Estado [BOE], n. 281, Madrid, España.

Londoño, B., Varón, A. \& Luna de Aliaga, B. (2012). El delito de trata de personas: Hacia la aplicación de estándares internacionales para la prevención, judicialización, protección y asistencia integral a las víctimas en Colombia. Revista de Derecho, 37, 198-230.

Magaña, D.M. (2017). Reflexiones en torno a la trata de mujeres con fines de explotación sexual desde la perspectiva de género. Alegatos, 95, 95-118.

Mansur, G. (2017). Trata de personas, tráfico de migrantes y la gobernabilidad de la migración a través del crimen. Etnografía, 21 (3), 541-554.

Maus, E. (2014). La trata de personas desde la perspectiva social y de derechos humanos en México. Estudios Judiciales, 14.

Maus, E. (2018). Trata de personas y derechos humanos. El Cotidiano, 209, 67-76. Mayordomo, V. (2011). Nueva regulación de la trata, el tráfico ilegal y la inmigración clandestina de personas. Estudios Penales y Criminólogos, 31, 325-390.

Oficina de las Naciones Unidas contra la Droga y el Delito (UNODC). (2009). Manual sobre la investigación del delito de trata de personas. Guía de Autoaprendizaje. Disponible en: https://www.unodc.org/documents/human-trafficking/ AUTO_APRENDIZAJE.pdf

Oficina de Publicaciones de la Unión Europea (OPUE). (2013). Los derechos de las víctimas de la trata de seres humanos en la UE.

Oficina Internacional del Trabajo (OIT). (2017). Estimaciones mundiales sobre la esclavitud moderna. Trabajo forzoso y matrimonio forzoso. Resumen ejecutivo. 
Disponible en: https://www.ilo.org/wcmsp5/groups/public/@ed_norm/@ipec/ documents/publication/wcms_596485.pdf

Olvera, J. \& Uribe, E. (2018). Algunas expresiones de la trata de personas, su invisibilidad y los retos en la dimensión preventiva. El Cotidiano, 209, 37-45.

Organización Internacional para las Migraciones (OIM). (2002). La trata de personas y los derechos humanos de los migrantes.

Organización Internacional para las Migraciones (OIM). (2013). Protocolo nacional unificado para la protección y asistencia integral a personas víctimas de trata. Disponible en: http://migracion.iniciativa2025alc.org/download/07ECg_Protocolo_Trata-.pdf

Organización Internacional para las Migraciones (OIM). (2018, 30 de julio). La mayoría de las víctimas de la trata de personas a nivel internacional cruzan los puntos fronterizos oficiales [Mensaje en un blog]. Disponible en: http:// rosanjose.iom.int/site/es/noticia/oim-la-mayor-de-las-v-ctimas-de-la-trata-depersonas-nivel-internacional-cruzan-los-puntos

Pomares, E. (2011). El delito de trata de seres humanos con finalidad de explotación laboral. Revista Electrónica de Ciencia Penal y Criminología, 15, 1-31.

Raymond, J. G. (2000). Guía para el nuevo protocolo de Naciones Unidas sobre el tráfico de personas. Dirección General de la Mujer.

Remiro Brotons, A. (2001). Protocolo contra el Tráfico Ilícito por Tierra, Mar y Aire que complementa la Convención de las Naciones Unidas contra la Delincuencia Organizada Transnacional. En Derecho internacional: tratados y otros documentos. Madrid, España: Mc Graw-Hill.

Remiro Brotons, A. (2001). Protocolo para Prevenir, Reprimir y Sancionar la Trata de Personas, Especialmente Mujeres y Niños que complementa la Convención de las Naciones Unidas contra la Delincuencia Organizada Transnacional. En Derecho internacional: tratados y otros documentos. Madrid, España: Mc Graw-Hill.

Reunes, M. (2018). Víctimas y victimarios. Un acercamiento a los procesos y las lógicas que configuran la trata de personas. El Cotidiano, 209, 77-84.

Reyes, J., Vargas, J. \& Aceros, J. C. (2017). Análisis de las medidas de asistencia a víctimas de trata de personas en Colombia en perspectiva de derechos humanos. Opinión Jurídica, 17 (33), 99-121.

Rodríguez, F. (2017). Abordaje Integral del Delito de Trata de Seres Humanos. Víctimas-Testigos (Estatuto de la víctima. Referencia a desaparecidos). Curso llevado a cabo en el Centro de Estudios Jurídicos, Madrid.

Sansó-Rubert, D. (2005). La internacionalización de la delincuencia organizada: análisis del fenómeno. UNINSCI Discussion Papers, 9, 47-61.

Save the Children. (2011). Investigación trata de personas con fines de explotación laboral y sus efectos en la niñez. 
Sociedad de Naciones (1904). Aprobación del Acuerdo Internacional Para la Represión de la Trata de Blancas. Disponible en: https://www.ohchr.org/sp/professionalinterest/pages/trafficinpersons.aspx

Sociedad de Naciones (1926). Convención sobre la Esclavitud de Ginebra. Disponible en: https://www.ohchr.org/sp/professionalinterest/pages/slaveryconvention.aspx

Torres, M. (2016). El nuevo rostro de un viejo fenómeno: la trata de personas con fines de explotación sexual y los derechos humanos. Sociología, 31 (89), 95-129.

Villacampa, C. \& Torres. N. (2012). Mujeres víctimas de trata en prisión en España. Revista de derecho penal y criminología, 3 (8), 411-494.

Villacampa, C. (2011). El Delito de Trata de Seres Humanos. Una Incriminación Dictada desde el Derecho Internacional. Navarra: Aranzadi.

Villacampa, C. (2011b). La nueva directiva europea relativa a la prevención y la lucha contra la trata de seres humanos y la protección de las víctimas. ¿Cambio de rumbo de la política de la Unión en materia de trata de seres humanos? Revista Electrónica de Ciencia Penal y Criminológica, 13-14, 1-52.

Willat, F. (6 de julio de 2006). ¿Qué es la perspectiva de derechos? [Mensaje en un blog]. Disponible en: http://democraciasur.com/2006/07/06/que-es-la-perspectiva-de-derechos/ 